\title{
Impacts of Attitude towards Online Banner Advertisement on Brand Awareness: Insight from Persuasive Hierarchy Model
}

\author{
Salem Mohamed S. Busen \\ Dept. of Communication, Sch. of MultiMedia Technology and Communication, \\ Universiti Utara Malaysia; Debo_debo10@yahoo.com \\ Che Su Mustaffa \\ Professor at the Dept. of Communication, Sch. of Multimedia Technology and \\ Communication Universiti Utara Malaysia \\ Mohamad Bahtiar \\ Senior Lecturer Dept. of Communication, Sch. of Multimedia Technology and \\ Communication Universiti Utara Malaysia
}

Doi:10.5901/mjss.2016.v7n3s1p81

\section{Abstract}

Researchers have noted that the visible progress of online advertising is not as actual as compared to the substantial amount of effort and resources advertisers have devoted into advertising through the digital medium. In view of these challenges, attention has been drawn to the need to examine the role of the dynamism of the antecedents which shape the awareness and performances of brand particularly in the Arab world. Therefore, based on this study's review, the importance and impacts of attitude towards online banner advertisements as an antecedents were identified. Similarly, in situating the antecedent within the model of persuasive hierarchy framework the study was able to explain the impact of awareness on brand performance. In conclusion, the study reviews have highlighted the significance of information on where online banner advertising campaigns should focus, which in turn affords for successful brand.

Keywords: Online banner advertisement, brand awareness, persuasive hierarchy

\section{Introduction}

The penetration of online activities into business and marketing dealing has being significantly changing and impacting consumers and brand relationship. In view of this, the impacts of consumers flocking the internet for online shopping and buying has become trending across the globe. Likewise, Benmamoun, Kalling and Cropf (2012) disclose that recent development in the Arab countries among which are Arab Spring and buying behaviours have been prompted by growing broadcast, Internet technologies and substantial absorption of shared information technologies by the Arab educated middle class and majorly young population. Considerably also, there have been changes in the Arab business behaviours mainly from the advertising sector. However, in recent time, expenses for online advertising are challenged by a noticeable flaw in brand accomplishments (Pfeiffer \& Zinnbauer, 2010). More importantly, online advertising has been influenced with about 5.4 declinations in the generation of revenue. Similarly, researchers have recorded that the visible progress of online advertising is not as actual (Cottle, 2011) as compared to the substantial amount of effort and resources advertisers have devoted into advertising through the digital medium. Nevertheless, the transient declination of the online advertising does not minimize the fact that online advertising is over taking the orthodox media in terms of performance and interactivity. Meanwhile, in view of these challenges, the dynamism of the antecedents which shape the awareness and performances have become imperative for further investigation. Consequently, there is a researchable gap in the context of discerning and assessing the impacts of online advertisement on brand awareness, which is relatively new particularly in the Arab world.

Stressing the impacts of some of the online advertisements antecedents, Choi and Rifon (2002) note that the abundant online advertisement information available to consumers pose a possible challenge to brand credibility and the eventual awareness. All the same, very little research on the rapidly changing advertising structure has been conducted 
in some parts of the developing society such as Libya. Up till the present, very little is known about the influence of new media on business and advertising environment (Ghannam, 2011). There is also a dearth of data on how the changing new media environment or landscape in Libya is affecting the public, and about public opinion concerning these developments.

Though, substantial amount of works have been done to study the impacts of online advertising but very little attention on the impact of consumers' attitudes towards online advertising on the brand awareness, in view of the fact that brand equity has emerged as a worthy concept to investigate when considering audience behavior change (Jarvis, Rhodes, Deshpande, Berry, Chulak-Bozzer, Faulkner, \& Latimer-Cheung, 2014). Also, the need for research attention cannot be over stretched in view of the cluttered online advertising environment, increasing online advertising designs, and the anticipated further progression of online advertising among consumers. Therefore, it becomes critical to understand the factors that affect consumer response and awareness. An essential benefit for conducting this study is a resultant absence of an in-depth (Cottle, 2011) and exhaustive research exploring and exploiting the effect of new communication technologies. Based on this, the paper conceptually examines the impacts of attitude towards online banner advertisement on brand awareness situating it within the model of persuasive hierarchy framework.

Therefore, this paper seeks to explore those mechanisms in the context of online advertisement that hold potency for brand awareness. There is no doubt that online advertisement antecedents are important driving forces in achieving brand success. However, the need to properly deploy the antecedents for brand awareness and customer purchase intention requires theoretical exploration. Similarly, the recent increase in online advertisement expenditures especially in the Arab world raises important questions on the importance of these driving forces as well as the need to understand their dimensions. There are also concerns from scholars on the influence of these antecedents.

\section{Overview of Online Advertising in Libya}

Libya advertising activities have been experiencing stiff control and regulation especially in the previous regime that limited its role in the economy. For instance, Libya had no Internet connections for most of the 1990s in spite of being comparatively wealthy compared to the developed countries (Maslen, 1996; Twati, 2014). For this reason, it is fair to conclude that online advertisement industry in Libya is still developing. Moreover, the use of technology (including communications technology) in Libya for a long time was marginal (Twati, 2014). This poor penetration could be the consequence of the strict regime control on media accessibility in other to limit public interactions.

However, currently the new trend among many young Libyans has shown that marketing has become an honorable subject (Fernandes, \& Pimenta, 2013). Currently Libya is gradually developing towards democracy and for that it is expected to activate marketing activities. Similarly, a country that is stable democratically is with a high probability of good penetration of communications media alongside freedom of the press and speech. Though, Libya is experiencing political turmoil, nevertheless, the sudden and irresistible political changes within the Arab world conveyed by the Arab Spring have covered the role of new media in other platforms such as advertising (Aouragh, 2012). Thereby in these Arab world buyers are becoming more and more aware of advertising and the influence of multi-media platforms. Meanwhile as a response to the growing and appealing online advertisement in some developing countries, such as Libya, multinational corporations (MNCs) from developed countries are speedily competing to penetrate these countries so to exploit the ever growing demands in emerging economies.

\section{Online Advertisement and Brand Accomplishments}

Online advertising was described by Bakshi and Kumar (2013) as a type of mass communication with premeditated message contents which are understandable, suitable and publishable over the Internet. Therefore, online advertisement is referred to as the broadcasting of advertisement messages on the Internet via websites, emails, ad-supported software, and smart-phones (Keller, 2009). According to Hsu and Hsu (2011) contemporary studies of online consumers now conceptualize them as active seekers of product related information. On the basis of this, online advertising was described by Bakshi and Kumar (2013) as a type of mass communication with premeditated message contents which are understandable, suitable and publishable over the Internet

In the study by Evans (2009) it was revealed that copious research has empirically identified the effects of online advertisement and the assessment of online advertisement on brand development. Danaher and Mullarkey (2003) also noted that the fundamental focus of these previous studies have emphasized the recall factors of advertisement, and design implementation of advertisement copy which coincided with Spalding et al, (2009)'s work. Similarly, several other studies (such as Manchanda et al., 2006; Lin \& Chen, 2009) have also contributed empirically to the comparative 
evaluation of the online advertisement and the conventional advertisement. As a result, Pfeiffer and Zinnbauer (2010) urged future researchers to examine the role of online advertisement on brand development and brand equity.

Essentially, online advertising exemplifies interaction through a direct communication of information about a product to a wide-ranging or precise audience. However, its efficacy is determined by several factors among which are: its headline framing, inclusion of animation, interplay, flash and use of color. Therefore, the success of equity brand depends on the product online advertising. This informs the reasons for the objective of this work which is to provide empirical evidence to the effectiveness of online banner advertising and determining the role of online banner advertising in developing brand equity.

\section{Characteristics of Online Banner Advertisement}

Considerably, many of the contents that are placed online are sustained by advertising (Goldfarb, \& Tucker, 2011). As we have it for television and radio, online resources also offer free access to contents through generation of revenue from advertising. Feasibly the most productive form of online advertising is the banner advertising (TechTerm, 2014). Online Banner advertisements are text and graphical displays that are hyperlinked to the uniform resource locator (URL) of the advertiser. The purpose of the online banner advertising mainly is to create awareness and draw the attention of the internet visitors on brand (Dreze \& Hussherr, 2003). Online banners advert may be either horizontal or vertical (Burns \& Lutz 2006; Rodgers \& Thorson 2000). These are the variety of online banner adverts sizes that are strategically used to turn customers mind around: (a) Standard Banner Advert: 468 x 60 Pixels, (b) Leader Board Banner Advert: $768 \times 90$ Pixels, (c) Banner Advert: 234 × 60 Pixels, (d) Skyscrapers advert: 120 × 600 Pixels, (e) Vertical Banner Advert 120 × 240 Pixels.

Online Banner advertising as the dominant form of advertising online represents $55 \%$ of all online advertisements (Faber, Lee, \& Nan, 2004; Interactive Advertising Bureau, 1999) and 32\% of all new media advertising revenue (Interactive Advertising Bureau, 2002, marketingterms.com, 2014). Commonly, online banner advertising is limited to a graphic image that characteristically appear as rectangular image shaped box that can be placed anywhere but usually positioned at the top, sides, or bottom of the web page.

\section{Attitude towards Online Banner Advertisement and Brand Awareness}

Online banner advertisements which are mostly displayed advertisements that are typically hyperlinked to an advertiser's website are the main form of advertising on the Web (Li, \& Bukovac, 1999). This popularity is because; the most productive form of online advertising is the banner advertising (TechTerm, 2014). As a result, considerably, many of the contents that are placed online are sustained by banner advertising (Goldfarb, \& Tucker, 2011). Even though predominantly used as Internet traffic builders, banner adverts have been presented to successfully raise brand awareness, preference, as well as purchase intentions (Briggs, \& Hollis, 1997). Similarly, Dreze and Hussherr (2003) stressed that previous research has revealed that exposure to banner advertising leads to improved advertisement awareness, brand awareness, purchase intention as well as site visits. Therefore, these findings indicate that banner adverts serve functions of both image as well as direct response advertising. Meanwhile, as image advertising, banner adverts can create brand equity. Also, as direct response advertising, banner adverts can stimulate traffic to advertised Web sites (Allen, \& Kania, 1997). In achieving this traffic, vibrancy is one of the unique innovational mechanisms of banner advertising, carrying moving images as well as graphics to enhance the presentation of persuasive messages (Ellsworth \& Ellsworth, 1995). However, in achieving the interactivity of online banner advertising, a number of high-tech developments which include JAVA script, plug-ins, Flash, in addition to streaming media have contributed (Yoo, Kim, \& Stout, 2004). Therefore, interactivity has become an important part of banner adverts for the reason that most animated banner adverts are a sequences of images superimposed on one another to build an illusion of motion (Kalyanaraman \& Oliver 2001).

The Internet and other interactive media such as interactive TV have been given different accolade as the powerful, responsive and customizable tool than the conventional media (Hoyer \& Macinnis, 2010; Port, 1999). However, indications from empirical studies support the uniformity of most audiences' reactions among Internet advertising and the more conventional advertising as regards the context of traditional measure of advertising usefulness. The study of Hoyer and Macinnis (2010) indicate that attitudes are centred on the beliefs or cognitions which shows that attitudes can be moulded based on beliefs and thoughts that we have about the information received. Once a consumer is exposed to the online advertising, there is possibility of either forming positive or negative attitudes towards the advertising (Schiffman and Kanuk, 2000). 
The study of Drèze and Hussherr (1999) for example, showed that audiences' response to Internet advertising is similar to audiences' response to other media advertising; just that Internet advertising is easier to ignore than others. In the same way, it was disclosed by Lynch and Ariely (2000) that consumers are not price alert when online advertisers offer different products as compared to that of identical products. This discovery nonetheless, completely refutes the findings in more conventional retail situations. The conventional determinant of advertising usefulness like attitude change, recall and brand choice are just a subcategory of the entire story of the effectiveness of online advertising. However, these measures are unavoidable as they are involved in the tradition of advertising research that aims at the effect of advertising on consumers; processes that make accessible little knowledge of what the audiences do with advertising (Fall, 2000). For the moment, the usual research viewpoint involves a captivating exposure to a kind of advertisement which is followed by several measure of receiver response. If the concept or belief that audiences respond to advertising, then the distinct nature of the dependent as well as independent variables is unclear. Definitely in actual fact, any kind of responses to any advertisement which include even just attending could be reliant on a number of other factors (Yoo, Kim, \& Stout, 2004). However, in a situation that audience select which they attend, then attending act turn out to be a very relevant factor of advertising response (Goldfarb, \& Tucker, 2011). Meanwhile, the predictable pattern for assessing effects and effectiveness of advertising has appropriately availed in the field (Rosenkrans, 2009); however it is increasingly confronted by the interactive context.

Online advertising can also generate warm feelings of friendliness, caring and hope (Solomon, 2009). Other than that, the unfavorable or negative feelings such as offence, defiance and others can also be generated through consumer's cognitive capacities (Mehta, 1999). According to Aaker and Stayman (1990) and Brown and Stayman (1992), the positive emotional response of consumers towards online advertising is the best indicator or criteria of effective advertising. This is because the objective to create advertising is to form a positive attitude in consumers towards the advertisement as well as the promoted goods and services.

\section{Brand Awareness and Effectiveness of Advertisement}

Brand awareness is the cynosure for measuring the effectiveness of an advertisement. It had been additionally underlined by Kelly (1991) that basic fundamental purpose of the complete advertising endeavours is to make and develop the awareness of a selected brand. It's solely cheap that buyers purchase product they're alert to. Inferably, an advertisement may be understood to be effective if it creates the attention of a selected product or brand as is reinforced by Macdonald and Sharp (1996). The most assumption in this study is on the utilization of the advertising of a brand in generating brand awareness that is in line with the work of Macdonald and Sharp (1993). Within the work of Macdonald and Sharp (1993), ninety four percent of their respondents believed that brand awareness is the measuring tool for the effectiveness of communication. Within the creation and development of brand awareness, as was earlier said, the foremost effective and renowned instrument is brand advertising. On another hand, the study of Peltier et al (1992) discovered that the most strategic action of direct response advertising is exclusively to instigate noticeable response from the recipients.

The proliferation of the IMC construct, has observed that some advertising messages duplicate the mixture of awareness and response function, later recording an incredible rational and emotional audience happen as seconded by Peltier et al. (1992).

Panel data was used by Robert, Ulrich and Michaela (2009) to analyse the influence of advertising on brand awareness and perceived quality.

The authors geared toward empirical reflection structuring and appraising advertising effectiveness; underscoring that organizations regard advertisement as a premeditated investment with the resolved of generating a good and winning brand, in conjunction with generating a solid brand awareness. It was disclosed from their study that there was a major positive and unwavering influence of advertising on brand awareness. In a similar study that was piloted in India, Roshni (2012) disclosed that $86 \%$ of brand of awareness is generated and sent using advertisement and offered a correlational table that portrayed a major association between advertising and brand awareness. It was again disclosed within the study that advertising is the basic instrument for communication wherever recipients most preferred to get information regarding their favourite brand. The study of Gan (2010) used a rather different from this study's, the researchers however used simple regression to assess the effectiveness of advertisement and identified a good significance of advertisement on the profit and worth of Malaysian corporations. The method procedure or approach adopted in the study encouraged the method approach of the study. Variety of different studies is showing up in this domain to empirically observe and appraise the impact of advertising or its relationships with brand equity and its development. Also, the study of Zahra (2012) used the statistical procedure (i.e. Structural Equation Modelling) to 
measure the function of multifarious mixture of promoting within the development of effective brand equity. Furthermore, Zahra (2012) in the study applied a broad range of sample size of household appliance users in Iran. The study showed some major effect of advertisement on brand awareness.

There are innumerable quantity of literature in this domain that has studied the effectiveness of advertising that the leading reason for developing advertising is to create awareness. A motivating index for effectiveness testing becomes, to what degree an advert will influence awareness within the minds of the audience/consumers as supported by Wells (1994), and Leavitt, Waddell and Wells (1970). Brand awareness as indicated by Rossiter and Percy (1991) isn't affected by simply the brand alone however the whole thought that unfold across from the brands' associated colours, shape and package and so on. This according to findings has been the motive for the advertisement and brand awareness development we have witnessed within the past studies as are often seen in the study of Romaniuk, Sharp, Paech and Driesener (2004). These authors studied the consumers' spontaneous and assisted brand awareness and advertising awareness, disclosing a major influence of assisted awareness within the purchase decision of buyers. As regards the awareness within the context of this study, the awareness could be a product of good advertising. Wells et al. (2003) agreed that advertising is an important instrument in creation of brand name awareness that successively develops effective brand equity.

\section{Persuasive Hierarchy Framework and Advertising Campaigns Focus}

For advertising scholars, the adaptation and applicability of the traditional advertising theories to online advertising has been of great concern since the advent of online advertising (Yoo, Kim, \& Stout, 2004). However, the traditional theories approaches continue to be applicable to the online advertising environment, for the reason that not only do the fundamental goals of online advertising are similar to the goals of traditional advertising (Pavlou \& Stewart 2000), but also the theoretical models advanced for traditional advertising have effectively been applied to online advertising (Cho 1999; Rodgers \& Thorson 2000).

Persuasive Hierarchy Frameworks are beyond any doubt the leading used models of persuasion (Dahl, 2012). Meanwhile, the essential postulation of the model displays that cognition is trailed by an effect, behavior, coherent thoughts turns to attitude growth that eventually ends up in purchase. The century-old advertising approach model, has received extensive attention from both the academic communities and practitioner as an explicit explanation of the way advertising works, as well as in turn, as a foundation for measuring the effects of advertising (Barry, \& Howard, 1990; Weilbacher, 2001). Because of its uncomplicatedness and logic, the persuasive hierarchy model offers information on where advertising campaigns should focus, which in turn affords for good advertising planning since the model acts as a theoretical tool to predict consumer behavior (Barry 2002).

Stimulating the active kind of cognition assumed within the Persuasive Hierarchy Models are Low-Involvement Hierarchy Models, that assume that (a low level of) cognition, i.e. simply being conscious of - instead of dynamically deliberating a team of brand, ends up in associate expertise followed by effect on attitude formation.

The Persuasive models presented the thought of a hierarchy of effects, which is an order within which things occur, with the consequence that the earlier effects are more important. Other multidimensional types of the persuasive hierarchy paradigm have been anticipated by several researchers among who are Maclnnis, Moorman, and Jaworski (1991), Bloom, Edell, and Staelin (1994).

The model with six levels of mental process (intermediate effects): (i) feature analysis resulting in mood generated effect, (2) basic classification resulting in pure effect transfer, (3) meaning analysis resultingin heuristic analysis, (4) information integration resulting in message based mostly persuasion, (5) role-taking resulting in empathy-based persuasion, and (6) constructive processes resulting in self-generated persuasion.

Meanwhile, Batra and Ray (1985) recommend that customers might develop a "hedonic" impact supported on pure feeling without an evaluation of exhausting product attributes. The multi spatiality in purchaser response, in line with Batra and Ray's framework, is thus the results of the various ways in which attitudes might develop (utilitarian versus hedonic), instead of the degree of elaboration. This implies that measures of affect ought to include utilitarian and hedonic elements. The application of persuasive hierarchy models highlight the significance of its involvement as a moderator of advertising effects. Cacioppo and Petty (1985) resolved that repetitions of various versions of an advert have a positive impact on low-involvement persons however no impact on high-involvement persons. In other words, repetition of a series of advertisements will forestall (or delay) wear-out. Therefore, the present study attempts to assess the effectiveness of online banner advertising within the framework of the persuasive hierarchy model. 


\section{Conclusions}

This discussion is premised on the theoretical direction and impacts of online banner advertisement on brand awareness.

The approaches taken are that of a general review and secondary research.

The theoretical propositions of persuasive hierarchy model regarding the potentials of online banner advertisement underlie this paper. Therefore, the paper responses to the initial proposition are in three-fold. Firstly, the importance of online banner advertisement on the essential brand awareness was established. Secondly, the awakening in the attitude of Libyan current generation on the online marketing and interactivity was identified. And lastly, the theoretical basis for online advertisement imperative in the molding favourable attitude toward brand was discussed.

The study presented in this article explores the role of source credibility in determining Web advertising effectiveness. Using traditional advertising effects theories, the study goes beyond recent investigations of vehicle effects on consumer response to banner ads. Specifically, the study examined the effects of website credibility and advertising credibility on ad credibility, ad and brand attitude, and product purchase intention. The effects of banner ad relevance (i.e., product category advertised to website editorial content) on consumer perceptions of the ad. These contributions are significant because they have enriched the analysis of Dreze and Hussher (2003), Rosenkrans (2009), who established that the conventional measures for evaluating the effectiveness of advertisement are still appropriate, suitable and reliable in line with online advertising. For instance, mainly procedures like establishing connection between online advertising and brand equity, brand recognition and brand awareness.

\section{References}

Allen, C. \& Kania, D. (1997). Web Catalog Cookbook. New York: John Wiley \& Sons.

Aouragh, M. (2012). Social media, mediation and the Arab revolutions. tripleC: Communication, Capitalism \& Critique. Open Access Journal for a Global Sustainable Information Society, 10(2), 518-536.

Bakshi, G. \& Kumar, S. G. (2013). Online advertising its impact on consumer buying behavior. International Journal of Research in Finance \& Marketing, 3(1), 21-30.

Barry, T. E. \& Howard, D. J. (1990). A review and critique of the hierarchy of effects. International Journal of Advertising Research, 9(2), 3-10.

Barry, T. E. (2002). In Defense of the Hierarchy of Effects: A Rejoinder to Weilbacher. Journal of Advertising Research, 42 (3), $44-47$.

Batra, R. \& Ray, M. L. (1985). "How Advertising Works at Contact," in Psychological Processes and Advertising Effects, Linda E Alwitt and Andrew A. Mitchell, eds. Hillsdale, NJ: Lawrence Eribaum Associates, 13-4.

Benmamoun, M., Kalliny, M., \& Cropf, R. A. (2012). The Arab Spring, MNEs, and virtual public spheres. Multinational Business Review, 20(1), 26-43.

Bloom, P. N., Edell, J. \& Staeliti, R. (1994). "Criteria for Assessing Research on the Effects of Marketing Communications," Working Paper No. 94-123. Cambridge, MA: Marketing Science Institute.

Burns, K.S. \& Lutz, R.J. (2006). The Function of Format. Journal of Advertising, 35(1), pp. 53-63. Retrieved January 11, 2007 from the Communication \& Mass Media Complete Database.

Cacioppo, J. T. \& Petty, R. E. (1985). "Central and Peripheral Routes to Persuasion: The Role of Message Repetition," in Psychological Processes and Advertising Effects, Andrew A. Mitchell and Linda F. Alwitt, eds. Hillsdale. NJ: Lawrence Eribaum Associates, 91112.

Cho, C. (1999). How Advertising Works on the WWW: Modified Elaboration Likelihood Model. Journal of Current Issues and Research in Advertising, 21 (1), 33-50.

Choi, S. M., \& Rifon, N. J. (2002). Antecedents and consequences of web advertising credibility: A study of consumer response to banner ads. Journal of Interactive Advertising, 3(1), 12-24.

Cottle, S. (2011). Media and the Arab uprisings of 2011: Research notes. Journalism, 12(5), 647-659.

Dahl, S. (2012). Advertising: step by step - or all at once? Retrieved November, 242014 from http://dahl.at/wordpress/2012/03/08/ persuasion-hierarchy-of-effects-theories/.

Danaher, P., \& Mullarkey, G. (2003) Factors affecting online advertising recall: A study of students. Journal of Advertising Research, $43(3), 252-267$.

Dreze, X. \& Hussherr, F. (2003). Internet Advertising: Is Anybody Watching? Journal of Interactive Marketing, 17 (4), 8-23.

Ellsworth, J. H. \& Ellsworth, M. V. (1995). Marketing on the Internet: Multimedia Strategies for the World Wide Web, New York: John Wiley \& Sons, Inc.

Evans, D. (2009). The online advertising industry: economics, evolution, and privacy. Journal of Economic Perspectives 23(3), 37-60. Evidence from the enlarging European Union, European Journal of Marketing, Vol. 41 No. 3/4, pp. 349-366.

Faber, R. J., Lee, M., \& Nan, X. (2004). Advertising and the consumer information environment online. American Behavioral Scientist, 48(4), 447-466.

Fernandes, P. O., \& Pimenta, R. E. (2013). The Portuguese consumer sentiment index toward marketing mix in crisis context. Tourism \& Management Studies, 9(1), 97-100. 
Ghannam, J. (2011). Social Media in the Arab World: Leading up to the Uprisings of 2011. Center for International Media Assistance, 3. Goldfarb, A., \& Tucker, C. (2011). Online display advertising: Targeting and obtrusiveness. Marketing Science, 30(3), 389-404.

Hsu, H. C., \& Hsu, S. M. (2011). A Study of Appeals and Argument Types on Web Advertisement. Web Journal of Chinese Management Review, 14(4), 1.

Interactive Advertising Bureau. (2006). Marketer \& Agency Guide to Online Game Advertising. Retrieved July, 2015 from http://legacy.iab.net/resources/admin/downloads/IAB\%20Guide\%20to\%200nline \%20Game\%20Advertising.pdf.

Jarvis, J. W., Rhodes, R. E., Deshpande, S., Berry, T. R., Chulak-Bozzer, T., Faulkner, G., \& Latimer-Cheung, A. E. (2014). Investigating the Role of Brand Equity in Predicting the Relationship Between Message Exposure and Parental Support for Their Child's Physical Activity. Social Marketing Quarterly,20(2), 103-115.

Kalyanaraman, S. \& Oliver, M. B. (2001). "Technology or Tradition: Exploring Relative Persuasive Appeals of Animation, Endorser Credibility, and Argument Strength in Web Advertising," Paper presented at the Annual Conference of the Association of Education in Journalism and Mass Communication, Washington, DC.

Keller, K. L. (2009). Building strong brands in a modern marketingcommunications environment.Journal of Marketing Communications, 15(2-3), 139-155.

Kelly, P. (1991). Advertising Research and Decision Making. Proceedings of the Australasian Marketing Educators' Conference, University of South Australia: Adelaide.

Leavitt, C., Waddell, C. and Wells, W. (1970). Improving day-after recall techniques. Journal of Advertising Research, 10(3), 13-17.

Li, H., \& Bukovac, J. L. (1999). Cognitive impact of banner ad characteristics: An experimental study. Journalism \& Mass Communication Quarterly, 76(2), 341-353.

Lin, Y-L., \& Chen. Y. W. (2009). Effects of Ad types, positions, animation lengths, and exposure times on the Click-Through rate of animated online advertisings. Computers \& Industrial Engineering, 57, 2, 580-591.

Lynch, J. G. \& Ariely, D. (2000). Wine Online: Search Costs and Competition on Price, Quality, and Distribution. Marketing Science, 19 (1), 37, 163-171.

Macdonald, E. \& Sharp, B. (1996). Management perceptions of the importance of brand awareness as an indication of advertising effectiveness. Marketing Research On-Line, 1, 1- 15.

Macinnis,D. J., Moorman, C. \& Jaworski, B. J. (1991). "Enhancing and Measuring Consumers' Motivation, Opportunity and Ability to Process Brand Information from Ads." Journal of Marketing, 55 (October), 32-53.

Manchanda , P, Dubé, J. P., GohK. Y.,\& Chintagunta. P. K. (2006). The effect of banner advertisingon Internet purchasing.Journal of Marketing Research 43, 98-108.

Marketingterms.com, (2014). Banner ad retrieved on the 17th november, 2014 from http://www.marketingterms.com/dictionary/ banner_ad/.

Mehta, A. (1999). Using self-concept to assess advertising effectiveness. Journal of advertising research. 81-89.

Pavlou, P. A. \& Stewart, D. W. (2000). Measuring the Effects and Effectiveness of Interactive Advertising: A Research Agenda. Journal of Interactive Advertising, 1 (1).

Peltier, J. W., Mueller, B., Rosen, R. G. (1992). Direct response versus image advertising. Enhancing communication effectiveness through an integrated approach. Journal of Direct Marketing, 6(1), $40-48$.

Pfeiffer, M. \&Zinnbauer, M. (2010). Can old media enhance new media? How traditional advertising pays off for an online social network. Journal of Advertising Research, 50(1), 42-49.

Port, O. (1999). Customers Move Into the Driver's Seat. Business Week, 103-106.

Robert, C. C., Ulrich, D. \& Michaela, D. (2009). The effect of advertisement on brand awareness and perceived quality: An empirical investigation using panel data. Quant Mark Econ, 7, 207-236.

Rodgers, S. \& Thorson, E. (2000). The Interactive Advertising Model: How Users Perceive and Process Online Ads. Journal of Interactive Advertising, 1 (1) <http://jiad.org/vol1/no1/Rodgers/>.

Romaniuk, J., Sharp, B., Paech, S., \& Driesener, C. (2004). Brand and advertising awareness: A replication and extension of a known empirical generalisation. Australasian Marketing Journal, 12(3).

Rosenkrans, G. (2009). The creativeness and effectiveness of online interactive rich media advertising. Journal of Interactive Advertising, 9(2), 18-31.

Roshni, P. S. (2012). Impact of advertising on brand awareness and consumer preference (with special refrence to men's wear). Journal of Business Management, 5(6), 54-61.

Schiffman, L. G. \& Kanuk, L. L. (2000). Consumer Behavior (7th ed.), Prentice Hall: New Yersey.

Solomon, D. (1995). DAGMAR: Defining Advertising Goals for Measured Advertising Results. (2nd Ed). Association of National Advertisers, Inc. NTC Publishing Group: Illinois USA.

Spalding, L., Cole, S. \&Fayer, A. (2009).How rich-media video technology boosts branding goals.Journal of Advertising Research 49(3),285-292.

Twati, J. M. (2014). The influence of societal culture on the adoption of information systems: The case of Libya. Communications of the IIMA, 8(1), 1.

Weilbacher, W. M. (2001). Point of View: Does Advertising Cause a "Hierarchy of Effects? Journal of Advertising Research, 41(6), $19-26$.

Well, W. D. (1994). Recognition, recall, and rating scales. Journal of Advertising Research, 4(3), 2-8.

Yoo, C. Y., Kim, K., \& Stout, P. A. (2004). Assessing the effects of animation in online banner advertising: Hierarchy of effects model. Journal of Interactive Advertising, 4(2), 49-60. 